\title{
Demonios, fantasmas y máscaras en la Antigüedad: consideraciones sobre el término larua y sus significados*
}

\author{
Alejandra Guzmán Almagro \\ alx_guz@yahoo.es \\ Demons, ghosts and masks in antiquity: larua concept considerations \\ and their meanings
}

\begin{abstract}
El presente artículo examina el término latino larua, aceptado comúnmente como espíritu maligno y vengativo y asimilado a otras entidades, en concreto con los lemures. Además, su empleo está atestiguado designando otros conceptos, como «máscara», que sin embargo guardarían una estrecha relación entre sí. A través de las diferentes fuentes documentales de época romana, se propone una actualización de las acepciones del término y la evolución de sus significados desde época republicana hasta los autores paganos tardíos.
\end{abstract}

Palabras clave: Laruae; espíritus; máscara; creencias romanas.
This paper examines the word larua, which has been commonly accepted as a revengeful evil spirit, in particular as a synonym of Lemur. Besides, it has other meanings such as «mask», although there is a connection between them. Through the different Roman sources examined, we suggest an updating of the meanings and their evolution from the Republic to the late pagan authors.

Key words: Laruae; spirits; mask; Roman beliefs.

Tradicionalmente, en el Más Allá romano cohabitaban diferentes tipos de criaturas que fueron denominadas con distintos términos más o menos específicos según su naturaleza, la cual los dividía fundamentalmente en aquellos seres positivos y favorables y aquellos negativos o perjudiciales. Mientras que el primer tipo, en donde los Lares familiares y los Penates, espíritus colectivos de los antepasados, encuentran un espacio relativamente consensuado entre las fuentes, dentro de la segunda tipología, la de los espíritus

* Este trabajo ha sido realizado en el marco de una línea de investigación en fase inicial vinculada al subprograma Ramón y Cajal MICINN-2011: Narrativas del Mal: demonología y exorcismos en la literatura latina, de las fuentes antiguas a Época Moderna. 
malignos, predomina una especie denominada en plural Laruae sobre la que son necesarias algunas consideraciones, pues la terminología romana, tan prolífica para asignar un nombre a las entidades divinas y sobrenaturales, parece ser un tanto vaga en este particular. A lo largo de los tiempos e incluso para los propios romanos, las almas de los difuntos que se convertían en seres malignos y acudían a la tierra para clamar venganza o atormentar a los vivos han sido llamadas genéricamente y casi de forma indistinta $L e$ mures y Laruae. Sin embargo, mientras que los primeros gozan de una gran concurrencia entre los autores e incluso cuentan con una celebración propia ampliamente atestiguada, en el caso de las laruae se plantean algunas dificultades para entender su origen, significado y sobre todo su uso, en vista de las variaciones que fue experimentando el término latino ${ }^{1}$. Es preciso puntualizar que no pretendemos aquí recoger y revisar el complicado aparato demonológico y escatológico antiguo presente en el mundo romano ([neo]pitagórico, [neo]platónico, oriental, etc.) ni tampoco las diferentes evoluciones de la concepción de la muerte y el alma, por bien que su influencia está muy presente en algunos de los autores que vamos a examinar y debamos recurrir en ocasiones a los conceptos griegos para matizar mejor algunas de las ideas, que planteamos desde una perspectiva esencialmente filológica.

\section{ENTIDADES MALIGNAS: GeNIOS Y ESPíRITUS DE DIFUNTOS}

De modo general, se ha considerado que Lemures y Laruae entran dentro de un grupo más amplio bajo la denominación de Manes o Dii Manes, espíritus de los antepasados que permanecen entre los vivos y que tienen connotaciones negativas para éstos ${ }^{2}$. Bajo este supuesto, ambos serían, pues, criaturas de naturaleza humana. No obstante, todo parece apuntar a que originariamente habría una distinción categórica entre las laruae y otras entidades relacionadas con los difuntos, puesto que aquéllas, si bien pertenecientes al ámbito

${ }^{1}$ Esta variación de significados y usos de larua a lo largo de los siglos y algunos interesantes paralelismos en griego pueden examinarse en el CGL 6, 1899, pp. 626-627, s.v. «Larva». Sobre la distinción entre Laruae y Lemures y su definición, véase como punto de partida Thaniel 1973. Además, Jobbé-Duval 1924, esp. pp. 122-123; Stramaglia 1999, pp. $27-$ 43, con bibliografía anterior.

2 Aun así, la denominación en plural Laruae correspondería a los espíritus más hostiles, como aquellos muertos de forma violenta, los biothanatoi. Jobbé-Duval 1924, p. 121; Cumont 1949, p. 83; Stramaglia 1999, pp. 27-43. 
infernal, no habrían tenido una existencia humana original ${ }^{3}$. Primero, en lo referente a la etimología del término, los propios romanos intentaron establecer un parentesco léxico y semántico entre Lares y Larvas, como si fueran las dos caras de una misma moneda y, de hecho, es la teoría frecuentemente aceptada, con una raíz común *lā-s y un origen netamente itálico, probablemente etrusco ${ }^{4}$. Varrón se refiere a Larvas y a Lémures como hijos de una misma madre, nombrada con diversos nombres, Mania, Lara o Larunda ${ }^{5}$. En consecuencia, las Laruae estarían contextualizadas dentro de la esfera del hogar y de las actividades domésticas (serían, pues, cercanas a los seres vivos) y en concreto guardarían una estrecha relación con los genios presentes en dicha esfera, los Lares. A la vez, serían divinidades particularmente nocivas en un entorno terrenal, pero no habrían gozado de una identidad humana anterior. A partir de aquí, el empleo del término larua $^{6}$ por parte de los romanos va a ir fluctuando entre su consideración de «genio», aproximándose al griego $\delta \alpha i ́ \mu \omega v$, si bien este término tampoco está exento de apreciaciones en los autores griegos ${ }^{7}$ y la de «difunto», y las fuentes van a permitir observar esta duplicidad e incluso una cierta evolución diacrónica de su significado.

${ }^{3}$ La crítica moderna ha continuado atribuyendo una confusa naturaleza a estos seres, incluyendo a los espíritus propiamente dichos y a los «fantasmas» (espíritus de los muertos que regresan) en una misma clasificación. Rose 1930 fue uno de los primeros en proponer la distinción entre Laruae, como aparición o esqueleto y Manes, como fantasma o cadáver. Las distinciones sucesivas en trabajos contemporáneos se encuentran recogidas por Felton 1999, p. 108.

${ }^{4}$ Se trata de una larga cuestión, planteada en los principales repertorios anticuarios y léxicos. Véanse Walde 1906, p. 326; Ernout y Meillet 1932, s.v. «Lar», p. 497, donde los Lares vendrían a ser en origen divinidades infernales convertidas en genios del hogar y donde, en concreto, Läruă tendría una formación etrusca. Véase además Hild en $D A G R$, «Larva», pp. 950-953, «Lemur», pp. 1100-1101, «Manes», pp. 1571-1576; RE 878-879, 806-814; ThLL 7, pp. 977-980, 1137-1139 y 8, pp. 293-299. Cf. además Martínez Maza 2000, p. 143, para la actuación de estos seres en el ámbito del culto doméstico y de las creencias populares.

${ }^{5}$ Varr., Ling. IX 38: uidemus enim Maniam matrem Larum dici e ibíd. VI 3.24. Cf. Taylor 1925.

${ }^{6}$ En singular y en plural, ya que la variación de número también va a permitir ver los matices de significado. También en nuestro trabajo, de forma deliberada, empleamos la mayúscula y la minúscula.

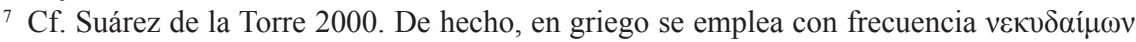
para referirse específicamente al espíritu de un difunto y diferenciarlo así de otros espíritus, cf. Preisendanz 1935, s.v. «Nekydaimon». Para las percepciones griegas de la muerte, de la vastísima bibliografía existente, remitimos aquí al trabajo aún capital de Rohde 1925, especialmente pp. 163-169 para este particular. 
Es muy posible que en época republicana, libre en los primeros siglos de la fuerte impronta escatológica griega posterior, predominara la idea de larua como un demonio o genio de naturaleza no humana. Podría confirmarlo el testimonio de Varrón, quien las consideraba hermanas de los genios buenos del hogar, los Lares («hijos de una misma madre»). Por consiguiente, las Laruae serían espíritus que habitarían entre los vivos y que los atormentarían sin motivo, ejercitando simplemente su naturaleza maligna. En este sentido, resulta muy interesante el empleo que Plauto hace del término en varios lugares de su obra. En la comedia Cautivos, Tíndaro se mofa del viejo Aristofonte apelando a su aspecto enfurecido: iam deliramenta loquitur, laruae stimulant uirum $^{8}$. Aristofonte está siendo literalmente azotado por las laruae, las cuales son culpables de su estado. De esta misma idea hace uso el comediógrafo en Anfitrión, donde refiere el estado de Alcmena como: nam haec quidem edepol laruarum plenast ${ }^{9}$. En esta ocasión, el personaje femenino está literalmente «lleno de larvas», es decir, poseído por espíritus. Y de nuevo, en Aulularia, el viejo Euclión se muestra fuera de sí: Laruae hunc at intemperiae insaniaeque agitant senem ${ }^{10}$. No será necesario insistir aquí en la identificación en la Antigüedad de la locura y de otras disfunciones mentales con la posesión, pero parece que el término laruatus es utilizado para designar específicamente a aquel individuo que está poseído por espíritus malignos y, por lo tanto, las laruae cumplirían con una función muy concreta. Nos hallamos ante un evidente paralelismo con la representación demoníaca procedente del mundo griego, según la cual las diferentes entidades divinas cumplen

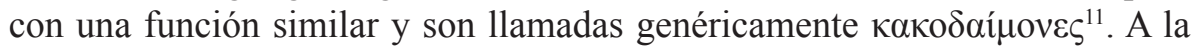
luz de los textos plautinos, larua está estrechamente relacionada a nivel semántico con insania y el propio comediógrafo se servirá de todo un abanico terminológico para describir a sus protagonistas enloquecidos-poseídos por malos espíritus. Por ejemplo, es llamativo el que parezca haber un uso indiscriminado de laruatus y de otro calificativo relacionado con lo sagrado como es cerritus, conectado con Cerus (y éste, a su vez, con Ceres) y, por lo tanto,

${ }^{8}$ Plaut., Capt. 598.

9 Plaut., Amph. 777.

${ }^{10}$ Plaut., Aul. 642.

${ }^{11}$ Nótese que Aristófanes, comediógrafo bien conocido por Plauto, hace uso de este término para referirse a los personajes que parecen estar bajo posesión. Para esta cuestión Stramaglia 1990, p. 24. 
con procesos extáticos en los que intervendrían divinidades ctónicas ${ }^{12}$. No hay que olvidar que Plauto escribía para ser entendido por su auditorio y, por ende, su testimonio deja pocas dudas sobre la naturaleza de las laruae en su tiempo. Éstas no tenían naturaleza humana y no eran, por lo tanto, almas de los difuntos, sino que estaban muy presentes en el mundo de los vivos como genios o espíritus involucrados en los procesos de locura (posesión).

Progresivamente, las laruae encontraron su ubicación en el mundo infernal, un espacio compartido con las almas de los difuntos. El temor que suscitaba este espacio provocó que cualquiera de sus moradores que regresaran, ante el pavor de los vivos, fuera confundido, por lo que fácilmente se produciría un intercambio de términos para designarlos, o quizás de roles. Como consecuencia, a la denominación genérica de Manes o Dii Manes, se sumarían otras subcategorías de espíritus, como decimos, según su grado de negatividad para con los vivos ${ }^{13}$. Mientras que los Manes son propiamente almas de los difuntos, ni buenos ni malos en principio, pero que deben ser venerados y asegurarse la quietud, los Lémures son las almas de aquellos difuntos que pueden regresar a reclamar algo a los vivos (apariciones fantasmagóricas de las que la literatura antigua ha dejado abundantes relatos) y las Larvas, aunque en origen «genios», son transformados en espíritus malignos, asimilados con los Lémures o incluso connotados de más negatividad que éstos. Y a pesar de todo, todavía parece haber una distinción entre los diferentes términos de acuerdo con las fuentes.

Los registros del término larua en época de Augusto son escasos, quizás por la voluntad de evitar ciertas palabras a causa de los tabúes religiosos dominantes ${ }^{14}$. Cuando los autores del período se refieren al mundo de los muertos, y, en concreto, de los muertos aparecidos, hacen uso de un vocabulario vago y de algún modo metafórico, rechazando cualquier concreción o distinción tipológica. Así, al relatar Tito Livio la historia del fantasma vengativo de Virginia, se

12 Plaut., Men. 890: num laruatust aut cerritus? O’ Brien 1924, pp. 18-19; Paschall 1939, pp. 60-62; Riess 1941, pp. 151-152; Stock 1996. Horacio utiliza el término cerritus con este sentido de «estar fuera de sí»: Hellade percussa Marius cum praecipitat se, cerritus fuit? (Sat. II 3. 274).

${ }^{13}$ Cumont 1922, p. 63; Dumézil 1966, pp. 365-367, señala que los Manes habrían sido en un origen divinidades itálicas abstractas semejantes a los démones griegos y alude a la propuesta etimológica manis, significando «bueno». Estas divinidades habrían sido asimiladas después con los difuntos, también Stramaglia 1999, pp. 32-33.

${ }_{14}$ Es la tesis sostenida, entre otros, por Thaniel 1973. Véase al respecto Uría Varela 1997, pp. $312-313$ y $320-324$. 
refiere a él como manes Verginiae ${ }^{15}$; Virgilio empleará en sus versos épicos denominaciones como simulacrum, imago ${ }^{16} \mathrm{o}$ umbra, los mismos a los que va a recurrir Plinio el Joven en su conocido relato de fantasmas, alternándolos con otros como effigies, eidolon (tomado del griego y que aparece ya en el infierno homérico) e incluso monstrum ${ }^{17}$. Sea como fuere, es evidente que en los tres ejemplos aportados de Livio, Virgilio y Plinio se alude a una realidad similar: entidades con una naturaleza humana que no han encontrado quietud en el infierno y/o regresan para dar un mensaje o una lección a los vivos. Consecuentemente, en estos casos quedaría justificado el empleo de formas que hacen alusión a las características propias de estas apariciones, como son la «imagen» (imago) del difunto que permite reconocerlo y que se corresponde con el ritual mismo de representarlo ${ }^{18}$ o bien su condición etérea y sombría. Por ende, resultaría inapropiado aludir a otros seres como las laruae, que quedarían fuera de esta tipología dada su condición sobrehumana.

Por el contrario, a pesar de la omisión de nombrar específicamente a los espíritus malignos como medida profiláctica, hacia finales de la República y durante el siglo I se desarrollaron extraordinariamente las ritualidades y celebraciones entorno a las divinidades infernales y a los moradores del infierno en general. Existían, por un lado, la obligación ancestral de honrar a los difuntos y, por otro, el respeto temeroso hacia su regreso ${ }^{19}$. Ovidio se ocupa

${ }^{15}$ Liu., Ab urb. III 58: manesque Verginiae, mortuae quam uiuae felicioris, per tot domos ad petendas poenas uagati, nullo relicto sonte tandem quieuerunt («y los manes de Virginia — el fantasma de Virginia-, más feliz muerta que cuando vivía, después de vagar por tantas casas reclamando venganza, al fin cuando no quedó ningún culpable, se apaciguaron»). Si no se indica lo contrario, aquí y en lo sucesivo ofrecemos una traducción propia de los textos.

${ }^{16}$ Por ejemplo, el famoso lugar de Aen. X 641: morte obita qualis fama est uolitare figura.

17 Plin., Epist. VII 27. 5-11. Para estos «fantasmas» vengativos y otros, véase Felton 1999, sobre todo las pp. 23-25 para una discusión sobre la terminología fantasmagórica. Monstrum o mostellum en diminutivo se encuentra ya en Plauto, quien dio este nombre a una comedia, Mostellaria, traducida con frecuencia como Comedia del fantasma. Según Jobbé-Duval 1924, p. 31, este término se emplearía específicamente en el caso de las casas encantadas, entendiendo el monstrum como una aparición o Poltergheist sin forma concreta.

${ }^{18}$ A pesar de que nos ocuparemos del significado de larua como «máscara», no somos de la opinión de que designe a este tipo de máscara funeraria, para la que se prefiere effigies o imago (Ou., Fast. 659: Scirpea pro domino in Tiberin iactatur imago). Obviamente, estas máscaras representaban a un difunto en concreto y conservaban sus rasgos para rememorarlo, por lo que no procede atribuirle las características negativas de una larua. No obstante, véase Dupont 1987 para las máscaras mortuorias, que vincularían la idea de larua con máscara aunque de forma indirecta.

19 Espinosa 2006-2007, pp. 262-263; Alfayé 2009. 
en los Fasti de recordar las Lemuria, fiestas que tenían lugar los días 9, 11 y 13 de mayo y que se celebraban para conjurar a los espíritus que podían vagar sobre la tierra causando estragos entre los ciudadanos. En concreto, el poeta identifica a los Lemures con espíritus vengativos y relaciona su origen con Remo (Remures, se habrían denominado en un principio), quien regresó para exigir venganza a Acca Laurencia y Fáustulo ${ }^{20}$. Ovidio no emplea en ningún lugar de su relato la palabra laruae, si bien hace uso de manes con significado análogo al de lemures y, por lo tanto, extiende de nuevo la negatividad a la totalidad de los difuntos: Manes exite paterni ${ }^{21}$. No obstante, Ovidio sí recurrirá a las laruae en otra de sus obras, una vez que se halle, sufriente, en el exilio, como veremos más adelante.

Revisemos ahora el aspecto crucial de la asimilación de las laruae al grupo de criaturas moradoras del infierno. Una característica que encontramos en la mayoría de autores es su capacidad para atormentar a los vivos, algo que ya constatábamos en los tiempos en que Plauto escribía sus comedias. La cuestión es dilucidar, en primer lugar, en qué medida las larvas tienen una naturaleza humana y si ejercen su maldad en la tierra a modo de aparecidos o si, por el contrario, son divinidades propiamente infernales. En segundo lugar, es preciso examinar el hecho mismo de dónde se ubican: si únicamente habitan en los infiernos o si ciertamente pueden regresar y están entre los hombres.

El dios Jano dicta un castigo ejemplar para aquellos mortales que sean divinizados, según relata el filósofo Séneca:

Qui contra hoc senatus consultum deus factus, dictus pictusue erit, eum dedi Laruis et proximo munere inter nouos auctoratos ferulis uapulare placet

Quienquiera que, en contra de este senadoconsulto, sea hecho, esculpido o pintado dios, sea entregado a las Larvas y molido a palos entre los nuevos gladiadores en el próximo espectáculo ${ }^{22}$.

La punición impuesta para aquel que no respete la sentencia es, en primer lugar, ser entregado a las Larvas, seres que tienen el encargo de martirizar en

${ }^{20}$ Ou., Fast. V 449-481. Para esta cuestión Thaniel 1973, pp. 183-185, donde recoge los comentarios al respecto de esta expresión ovidiana y también Espinosa 2006-2007, pp. 262-263.

${ }^{21}$ Aparte de los «manes de Virginia» relatados por Plinio, véase Suetonio, Ner. 34: manes Galbae y Cicerón, aún en época republicana, con un uso semejante en Pis. 16: coniuratorum manes mortuorum expiare. Para Lemures y Lemuria véase además Lux 2004, con bibliografía.

22 Sen., Apoc. IX 3 (trad. Gil 1971). 
el ámbito de ultratumba. Más explícito, aunque en la misma línea discursiva, resulta Plinio el Viejo, quien en su Historia Natural apunta a la ubicación infernal de estos seres, pero a un origen no humano de los mismos ${ }^{23}$ :

Nec Plancus inlepide, cum diceretur Asinius Pollio orationes in eum parare, quae ab ipso aut libertis post mortem Planci ederentur, ne respondere posset: cum mortuis non nisi laruas luctari ${ }^{24}$.

Planco no fue un ignorante: se decía que cuando Asinio Polión preparaba un discurso en su contra que sólo sería editado por él o sus hijos tras la muerte de Planco para que éste no pudiera contestarlo, dijo: «Contra los muertos no luchan sino las larvas».

Dos hombres de ciencia, conceptual y terminológicamente precisos, de una misma época como Séneca y Plinio sitúan a las larvas entre los muertos, pero con la función específica de castigarles en el infierno. Laruae vuelven a ser a la luz de estos testimonios seres demoníacos con una naturaleza distinta a los espíritus de los difuntos. Sirva de apoyo a las fuentes literarias el elocuente testimonio que brinda una defixio de finales del siglo II, procedente de Petronell (antiguo Carnutum, Austria), que clama justicia ante las divinidades infernales y un gran castigo, el de la muerte inmediata y posterior martirio inter laruas para la víctima, a la sazón un tal Eudemo:

Sa〈nc >te Dite(!) pa/ter et Vera/cura(!) et Cerber/e auxilie(!) q<u>i tenes / limina inferna sive / \{sive\} superna / Voces Mágicas (?) / v[os] pre[co]r fa[ci]a[tis] / [Eudemum(?) ---a(?)]d r[egnum(?) inf]/ernum quam cel[e]ris〈s $>$ i[me](!) / infra dies nove〈m〉 (!) va/sum(!) reponat defigo Eudem [um] / nec[et]i[s] eum pes<s>imo leto ad inf[er]os / [duca]tis eundem recol 〈l〉igatis / $\mathrm{m}[\mathrm{anibu}] \mathrm{s}$ ministeria infernorum / [d]eu[m(!) quom]od «o i[1]<l>e(!) plu<m>bus(!) po<n>dus h<a bet sic et / [E]ud<e>mus $\mathrm{h}\langle\mathrm{a}\rangle$ beat $\mathrm{v}[\mathrm{o}] \mathrm{s}$ iratos inter la〈r>vas / [---]ate ia〈m〉 hostiat quam celeris $\langle\mathrm{s}\rangle \mathrm{im}<\mathrm{e}\rangle(!) / \mathrm{m}[---](?)^{25}$

${ }^{23}$ Contra esta afirmación, Jobbé-Duval 1924, pp. 86-87, quien, citando el mismo texto de Séneca, consiente en que, como los muertos o al menos determinados muertos son percibidos como negativos, es lógico que se ocupen de torturar a los recién llegados: «Néanmoins, ennemies des vivants, elles (i.e., las larvas) l'étaient également des autres morts. Méprisées par ces derniers, elles les persécutaient».

${ }^{24}$ Plin., Praef. H.N. 31.

${ }_{25}$ Es la lectura de Kropp 2008. Cf. $A E$ 1929, 228. Egger 1962, pp. 81-97 y Marco 2010, pp. 580-581, cuya traducción seguimos parcialmente. 
Dis Pater santo y Verecura y Cerbero auxiliar, que tienes los umbrales inferiores y superiores (voces magicas), os ruego que enviéis a Eudemo ... al reino infernal lo más rápidamente posible, que reponga el vaso antes de nueve días. Consagro a Eudemo, procuradle una pésima salida, conducidlo a los infiernos, reunidlo con los Manes, ministerios de los dioses infernales. Del mismo modo que este plomo pesa, que así os tenga airados Eudemo. Entre las larvas ... que sea víctima lo más rápido posible ...

\title{
II. LAS CARAS DE LA LARUA: MÁSCARAS Y ESQUELETOS
}

En medio de tan conspicuo material religioso-fantasmagórico perteneciente a la primera mitad del siglo I, un autor va a atestiguar la palabra larua en sus escritos, pero lo hará con un significado diferente. Una sátira de Horacio nos habla de un personaje al que se le pide que interprete una danza a imitación del cíclope Polifemo:

\begin{abstract}
At illi foeda cicatrix saetosam laeui frontem turpauerat oris.

Campanum in morbum, in faciem permulta iocatus, pastorem saltaret uti Cyclopa rogabat; nil illi larua aut tragicis opus esse cothurnis ${ }^{26}$.
\end{abstract}

Y aquella fea cicatriz le había desfigurado la peluda sien izquierda. Al reírnos de esta enfermedad propia de la Campania, le pidió que bailara la danza pastoral del Cíclope, pues no le hacían falta ni máscara ni trágicos coturnos.

Es decir, larua, utilizado aquí llamativamente en singular, tiene un significado que difiere de lo revisado hasta ahora, puesto que Polifemo es un ser monstruoso, si se quiere, sobrenatural, pero no un fantasma o un demonio. Aunque sea sólo en apariencia y pueda establecerse una relación, existe una distancia entre este sentido del término (máscara) y el contexto en el que se emplea (un discurso satírico) con los anteriores registros de laruae. No cabe duda de que, a menudo, al elemento terrible acompaña el elemento grotesco como recurso apotropaico y cabe recordar además la práctica de representar plástica y teatralmente a determinadas divinidades y seres sobrenaturales, precisamente con esa voluntad profiláctica. Por otro lado, nos

\footnotetext{
${ }^{26}$ Hor., Sat. I 5.64 .
} 
parece necesario recuperar aquí la idea de que la máscara guarda una estrecha conexión con la muerte, no en vano términos como imago, effigies y similares pasan a denominar a los fantasmas, como si éstos fueran una especie de «doble», como hemos visto, en autores del siglo I entre los que se encuentran Virgilio o Plinio, aunque ya hemos apuntado a que es poco probable que la designación específica de larua se empleara para la máscara mortuoria que identifica y rememora a un antepasado ${ }^{27}$. Más bien debemos recurrir nuevamente al mundo griego hasta hallar, por ejemplo, a la representación de Mormo, un espectro que, junto con las Lamias y otros seres infernales, forma el cortejo de la diosa Hécate. Mormo tiene su materialización en un ente fantasmagórico que aterroriza a los niños y que se

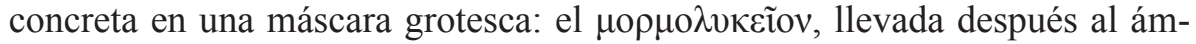
bito del teatro a través de un proceso de dramatización del ritual ${ }^{28}$. Por lo tanto, el poeta de Venusia utiliza aquí el término apropiado y específico en este tipo de representaciones teatrales (máscaras grotescas, monstruosas) y no lo elige por la comodidad que ofrece el tono satírico del discurso, como ha sido propuesto ${ }^{29}$.

Si en el texto de Horacio hemos hallado larua en singular como una visión monstruosa y sobrenatural que se materializa en una máscara teatral, hay que regresar ahora a su forma plural e intentar hallar aún más elementos relacionantes a fin de poder definir mejor los matices semánticos y conceptuales. Un testimonio que aúna el aspecto monstruoso y su conexión con el mundo infernal lo brinda un epigrama de origen norte africano del siglo III donde el poeta, al parecer poco amigo de la creciente población procedente del sur del Sáhara en la ciudad de Hadrumeta, alude con disgusto al pueblo de los garamantes, expresándose en estos términos:

${ }^{27}$ Cf. supra nota 18.

${ }^{28}$ Patera 2005. También para el empleo de máscaras en ciertos rituales y su conexión postrera con el teatro en Grecia cf. Meuli, 1975, vol. 2, pp. 263-266; Faraone 1993, pp. 197-198; Iles Johnston 1995, p. 365, n. 9. Para la transformación de seres mitológicos monstruosos en máscaras Hedreen 2007. Finalmente, para la evolución del término en estos dos significados véase sustancialmente Bronzini 1991.

${ }^{29}$ Así Thaniel 1973, p. 187: «One argument in answer to this could point out the taboo aspect of the words which made them unsuitable for higher poetry, whereas Manes, being a euphemistic word, was acceptable and frequently used. The fact that the words are found in Horace's lighter poetry, the Satires and the Epistles, but not in the more serious Odes, seems to support the hypothesis»». 
faex Garamantarum nostrum processit ad axem

et piceo gaudet corpore uerna niger,

quem nisi uox hominem labris emissa sonaret,

terreret uisu horrida larua uiros.

dira, Hadrumeta, tuum rapiant sibi Tartara monstrum:

custodem hunc Ditis debet habere domus ${ }^{30}$.

la chusma de los garamantes avanza hacia nuestro mundo y el esclavo negro se alegra en su cuerpo oscuro; él, que si su voz no sonara humana al salirle de los labios, aterrorizaría hasta a los más hombres con su aspecto de horrible larva. Hadrumeta, deja que los prodigios del Tártaro se lleven a este monstruo tuyo: la casa del Dios de los infiernos bien lo merece de guardián.

El texto, si bien algo tardío, resuelve de otro modo la relación entre la criatura con su correspondencia visual, por lo que justifica el empleo del término en singular y, de paso, sitúa a este «monstruo» en el ámbito infernal, donde parece que ya ha quedado relegado desde épocas anteriores. Resulta interesante el color negro del esclavo sudafricano, color semejante al de una larua. Sin abundar demasiado en esta cuestión, recordaremos aquí que el color negro de los espíritus infernales, incluyendo al de los difuntos aparecidos, está presente en algunas fuentes, a pesar de que no hay registros específicos de este calificativo para las laruae salvo este testimonio ${ }^{31}$.

Pasemos a continuación a la cuestión de cómo y dónde habría acontecido la transformación de las laruae en espíritus vengativos y la asimilación/confusión con los Lémures y los fantasmas en general. En el trascurso del siglo I destacan los autores que registran un nuevo significado de larua. En primer lugar, disponemos de un ejemplo del empleo del término, aquel que ofrece Petronio al narrar las excentricidades de Trimalción:

${ }^{30}$ Bucheler y Riese 1864, n. 183, pp. 155-156.

${ }^{31}$ La negritud sí está contrastada en el caso de los Lemures, por ejemplo, en Pers., Sat. V 185: tum nigri lemures ouaque rupto. Los fantasmas y las criaturas infernales en general también están asociados al color negro, hasta el punto de que se empleaban actores negros para interpretarlos si atendemos a Suet., Cal. LVII 10: Parabatur et in noctem spectaculum, quo argumenta inferorum per Aegyptios et Aethiopas explicarentur. Por este motivo, no es improbable que en el texto africano citado se emplee a la larua como denominación general de criatura infernal. Para esta cuestión véase Winkler 1980, quien cita numerosas fuentes para conectar la negrura con la noche y con el infierno pero que, sin embargo, atribuye a las larvas un color pálido, p. 162; Stramaglia 1999, pp. 38-39; Lux 2004, pp. 12-13. Remitimos para la relación con la noche al trabajo de Ogden 2008. 
Potantibus ergo nobis et accuratissime lautitias mirantibus laruam argenteam attulit seruus sic aptatam, ut articuli eius uertebraeque luxatae in omnem partem flecterentur ${ }^{32}$.

Mientras bebíamos y admirábamos la magnificencia del banquete, trajo un esclavo un esqueleto de plata, tan bien hecho que sus articulaciones y vértebras móviles podían girarse en todas direcciones.

Se trata de un texto recurrente para fijar otro de los significados de larua, en singular, el de «esqueleto». No hay duda de que hay una asimilación del término con la representación última de la muerte, esto es, la imagen de un cadáver humano o de lo que queda de él en última instancia, una idea presente en diferentes épocas y en numerosas mentalidades. La cultura material aporta valiosos testimonios sobre este particular y no es insólito el hallazgo de representaciones precisas de esqueletos en cerámica o en gemas esculpidas, significando el mundo infernal, hecho que está relacionado en gran medida con la idea de la brevedad de la vida y el memento mori, con un carácter probablemente epicúreo ${ }^{33}$. Lo más llamativo es que vuelve de nuevo a haber una conexión entre la «imagen» (imago, eidolon), si bien de forma inconcreta, no relacionada por su aspecto con un individuo sino con la generalidad humana y no cabe duda de que el esqueleto, además de ser un recordatorio de en qué nos convertimos físicamente, representa también, bajo el término larua, a los espíritus de los difuntos y en concreto a los espíritus malignos. Encontramos nuevamente un doble significado, esta vez el que ofrece la representación iconográfica. De una parte, larua significando la Muerte, mostrando su aspecto último, como enseña Trimalción. Pero de otra parte y de forma más precisa, el esqueleto, denominado larua, es la representación del espíritu y en particular de los espíritus malignos y vengativos. Es la teoría que apuntó hace ya más de tres siglos Gotthold E. Lessing en su clásico tratado sobre la representación de la muerte en la Antigüedad, argumentando en contra de la simple asimilación del esqueleto con la muerte ${ }^{34}$. Las laruae cobran un aspecto esquelético en el Más Allá y antes que Petronio

${ }^{32}$ Petron., Sat. XXXIV 8.

${ }^{33}$ Parkes Weber 1910, pp. 7-8 y 114-117, cita como ejemplo más elocuente al vaso de plata del llamado «tesoro de Boscoreale», conservado en el Museo del Louvre y que data del siglo I de nuestra era. Sus relieves muestran esqueletos atormentando a los difuntos.

${ }^{34}$ Lessing 1769 (consultado en la reedición inglesa de 1914), especialmente pp. 215-218 para este particular. 
y desde su exilio, Ovidio utiliza el término con este sentido, el de «esqueleto» como larua, en Ibis:

Tunc quoque, cum fuero vacuas dilapsus in auras, exanguis mores oderit umbra tuos;

tunc quoque factorum ueniam memor umbra tuorum, insequar et uultus ossea larua tuos ${ }^{35}$.

Incluso entonces, cuando me vaya disuelto en vacuos aires, mi sombra exangüe odiará tu pasado; también entonces mi sombra vendrá a recordarte tus acciones y perseguiré tus visiones como huesuda larva.

Sólo si identificamos al esqueleto con su naturaleza demoníaca se comprende la sentencia de Séneca: nemo tam puer est ut Cerberum timeat et tenebras et laruarum habitum nudis ossibus cohaerentium ${ }^{36}$ («nadie es tan niño que tema a Cerbero, a las tinieblas y al vestido de las larvas compuestas por huesos desnudos»). En otras palabras: el filósofo corrobora que estos seres están en el ámbito infernal y que tienen la apariencia de esqueleto y, además, no traicionaría al texto de la Apocolocyntosis, donde las larvas atormentan a los muertos. A nuestro juicio, sí difiere del texto ovidiano anterior, que si bien parece reflejar una misma idea, utiliza larua en singular y para referirse a sí mismo en el Más Allá (un espíritu de difunto vengativo con una identidad concreta) ${ }^{37}$. Este es el panorama evolutivo del término al menos en época clásica y de acuerdo con una construcción cultural que, sin duda, parece priorizar la vertiente popular. Laruae serían genios malignos, ubicados después en el inframundo y asimilados con las almas vengativas de los difuntos. Aun en esta última instancia, seguirían cumpliendo en la mayoría de casos su función demoníaca negativa, puesto que en el infierno se les habría asignado el rol de castigar a las almas humanas. Además, tendrían una clara representación gráfica, pasando quizás por su conexión a la iconografía fu-

35 Ou., Ib. 144. A pesar de que hay cierta complejidad textual en el verso, que ofrece la variante forma por larua en algunas ediciones. Nosotros seguimos la lectura larua. La secuencia completa así lo aconseja (si bien forma se emplea también con este propósito), con la repetición de umbra y el adjetivo ossea, que remite inevitablemente a la imagen del esqueleto.

${ }^{36}$ Sen., Epist. III 24.18.

${ }^{37}$ Lo que sustentaría la afirmación de Jobbé-Duval 1924 referida en nota 23 de este trabajo. 
neraria (imago, simulacrum), que se transformaría en grotesca («máscara») y en simbólica («esqueleto»), horrenda en cualquier caso. Es llamativo que bajo esta apariencia asuste a los niños, como hacen las representaciones enmascaradas de Mormo y similares. En definitiva, las fuentes que nos hablan de las laruae sostienen una determinación semántica bastante clara para referirse a ellas.

\section{EVOLUCIÓN CONCEPTUAL}

A partir del siglo II y en lo sucesivo, parece surgir una confusión de conceptos, pero quizás únicamente en un ámbito filosófico-teológico, alejado en gran medida de la tradición popular. Así llegamos a Apuleyo, cuyo texto ha sido empleado a menudo para ilustrar mejor el significado del término que nos ocupa ${ }^{38}$.

Est et secundo significatus species daemonum animus humanus emeritis stipendiis uitae corpore suo abiurans. Hunc uetere Latina lingua reperio Lemurem dictitatum. Ex hisce ergo Lemuribus qui posterorum suorum curam sortitus placato et quieto numine domum possidet, Lar dicitur familiaris; qui uero ob aduersa uitae merita nullis (bonis) sedibus incerta uagatione ceu quodam exilio punitur, inane terriculamentum bonis hominibus, ceterum malis noxium, id genus plerique Laruas perhibent. Cum uero incertum est, quae cuique eorum sortitio euenerit, utrum Lar sit an Larua, nomine Manem deum nuncupant. $^{39}$

También hay, según su significado, un tipo de demonio, si el alma humana abandona su cuerpo pidiendo recompensas debidas en vida. A éste, en lengua latina se solía llamar Lémur. De estos lémures aquel que ha sido aplacado por sus descendientes y preside el hogar es llamado Lar familiar. Pero el que, a causa de su vida no ha merecido ningún honor, vaga sin sede segura y, puesto que se le castiga con este exilio, horriblemente castiga a los hombres buenos y malos: a este tipo pertenecen las larvas. Cuando ciertamente es difícil distinguir si se trata de un Lar o de una Larva, se les denomina Manes.

Ciertamente, Apuleyo se expresa en este tratado recogiendo lo que ya había afirmado Varrón y se hace eco del doblete Lar-Larua, asignando a ambos una

${ }^{38}$ Hidalgo 2009-2010.

39 Apul., De deo Socr. 15. 
identidad humana. Al mismo tiempo se hace eco de las tradiciones demonológicas de línea platónica, puesto que autores como Plotino y a su vez san Agustín, quien lo cita, también consideran que las almas de los difuntos se transforman en daimones y que se llaman Lares (aquí se adapta el de Hipona al imaginario romano) si son buenos, Lémures o Larvas si malos y Manes si son indeterminados ${ }^{40}$. Pero hay que tener en cuenta que con Agustín y los primeros ideólogos cristianos comienza toda una serie de adaptaciones de la demonología pagana, por lo que en este punto la confusión entre laruae y lemures como las almas de los malvados transformadas en demonios es inevitable y ya no es necesaria tanta precisión terminológica ${ }^{41}$. Dicho esto, si regresamos al pagano Apuleyo, es posible comprobar cómo el mismo autor recupera otra vieja acepción, aquella original que ofrecía Plauto y que relacionaba a las laruae con la posesión: uel rursum mitigato conciliari marito uel, si id nequiuerit, certe larua uel aliquo diro numine immisso uiolenter eius expugnari spiritum ${ }^{42}$. Siguiendo esta idea, construye Apuleyo en varios lugares las derivaciones sobre larua,

${ }^{40}$ Aug., De ciu. Dei IX 11: Dicit quidem et animas hominum daemones esse et ex hominibus fieri lares, si boni meriti sunt; lemures, si mali, seu laruas; manes autem deos dici, si incertum est bonorum eos seu malorum esse meritorum («Dice [Plotino] también que las almas de los hombres son démones y que de los hombres surgen los lares si merecen el bien, lémures o larvas si son malos; dioses manes se llaman cuando es incierto si merecen bien o mal...»).

${ }^{41}$ Por citar algunos lugares tempranos: haciendo una distinción, todavía Porfirio, Schol. ad Hor. II 2.209: lemures, umbras uagantes hominum ante diem mortuorum et ideo metuendas ... umbras terribiles biothanatorum, que recoge la idea griega de los biothanatoi como fantasmas vengativos por excelencia. Nonio Marcelo, gramático del siglo IV, mezcla las apariciones con forma humana (los fantasmas) con otras apariciones terroríficas, De comp. doctr. (ed. Lindsay 1903), 135: Lemures: laruae nocturnae et terrificationes imaginum et bestiarum, contribuyendo a la tradicional confusión entre ambas entidades. Isidoro (Oríg. VIII 11.101) sigue la corriente de Agustín en las Etimologias: Laruas ex hominibus factos daemones aiunt, qui meriti mali fuerint. Quarum natura esse dicitur terrere paruulos et in angulis garrire tenebrosis. Curiosamente, Tertuliano, en su De anima, no emplea el término que nos ocupa. La transformación de las larvas en el universo cristiano se resume bien en Jobbé-Duval 1924, p. 34: «Notons-le enfin, les écrivains chrétiens dotèrent des qualités funestes des larvae les démons, tels qu'ils les concevaient, les anges déchus qui, eux aussi, pouvaient être exorcisés», con algún ejemplo más.

${ }^{42}$ Apul., Met. IX, 29. Seguimos el texto de Rubio 1978, p. 274: «o que calme a su marido y reconcilie el matrimonio, o, si esto no le fuera posible, que suscite al menos algún fantasma o alguna divinidad infernal para poner violentamente fin a sus días». Concordando con la opinión de Stramaglia 1990, p. 24, descartamos que laruatus signifique «poseído por fantasmas», sino mejor por divinidades malignas, similar al adjetivo cerritus al que nos hemos referido en este trabajo, nota 12. 
como en el mismo libro: horrenda Proserpina triformi facie laruales impetus comprimens $^{43}$, donde resuena el sentido de larva como divinidad sobrenatural y furibunda cuyos ataques controla, justamente, la reina de los infiernos, Proserpina. Por último, toma el madaurense el término larua en su ámbito más plástico, que dota a los difuntos de una apariencia cadavérica, esquelética, y aporta un dato más sobre el uso de determinadas representaciones de laruae en la magia. Ocurre en la Apología, cuando se le acusa de utilizar una figura en forma de esqueleto con finalidades necrománticas. Apuleyo se defiende arguyendo que se trata de una estatuilla de Mercurio:

Hiccine est sceletus, haeccine est larua, hoccine est quod appellitabatis daemonium? Magicumne istud an sollemne et commune simulacrum est? ${ }^{44}$.

¿Es esto un esqueleto?, ¿una larva?, ¿es lo que solíais llamar demonio? ¿Es acaso una imagen mágica o por el contrario una figura consagrada y corriente?

Por un lado, la secuencia apunta a una cierta sinonimia sceletus - larua daemonium, con una progresión que iría de la concreción material (la figurilla) al concepto que representa. Por otro lado, la argumentación de Apuleyo permite adivinar que el plano discursivo no corresponde a una argumentación filosófica, sino a un intento de desprestigiar las creencias populares: quien cree en fantasmas y espectros es un supersticioso ${ }^{45}$ o un practicante de magia él mismo, denominado laruans, un sugerente participio activo formado a partir del sustantivo. ${ }^{46}$

${ }^{43}$ Met. XI 2.

${ }^{44}$ Apul., Apol. 63.6.

${ }^{45}$ Apuleyo sostiene además que sus detractores creen en todos estos fantasmas y espectros infernales con un temor infantil (como decía Séneca) y que él, al contrario, siendo un platónico, conoce bien el destino de las almas: ibid. 64.3: ceterum Platonica familia nihil nouimus nisi festum et laetum et sollemne et superum et caeleste («los que pertenecemos a la estirpe platónica sólo conocemos lo que es brillante y gozoso, sagrado, superior y celestial»).

${ }^{46}$ Apol., 63.9: hunc qui sceletum audet dicere, profecto ille simulacra deorum nulla uidet aut omnia neglegit. Hunc denique qui laruam putat, ipse est laruans («el que se atreva a decir que esto es un esqueleto, sin duda no ha visto ninguna imagen sagrada o no les practica culto. Quien cree que esto es una larva, es que es él mismo un conjurador de espíritus»). A pesar de algunas lecturas que proponen laruatus, nos inclinamos a aceptar la lectio communis pues, como decimos, sugiere interesantes derivaciones léxicas del término. Frente a la forma deponente laruari ('estar poseído por las larvas, estar enfurecido'), parece más adecuado emplear la forma activa laruare ('estar en contacto con las larvas', 'invocar a las larvas' e incluso '«crear» larvas de forma plástica'). Cf. Hunink 1996, p. 160. 
En síntesis, el recorrido por los textos donde se registra el término larua, en singular y plural con sus diferentes acepciones, permite proponer las siguientes afirmaciones:

1. Laruae (plural): Seres sobrenaturales de origen itálico; genios malignos relacionados con el hogar y, por extensión, con los Lares. Son agentes que intervienen en la posesión. Este empleo sucede en épocas tempranas, a la luz de Plauto, pero se mantiene a lo largo de toda la Antigüedad y genera adjetivos tales como laruatus ('enfurecido, poseído').

2. Laruae (plural): Seres infernales, confundidos en ese espacio subterráneo con espíritus de los difuntos. Sin embargo, en algunos casos su naturaleza parece no ser humana, ya que en el infierno tienen reservada la función de hostigar y martirizar a las almas, tal y como recogen Séneca, Plinio y algún testimonio de vía «popular» como son las defixiones.

3. laruae (plural): Espíritus de difuntos malvados y también de aquellos que, por algún motivo, no están en paz (biothanatoi, entre otros) y que regresan al mundo de los vivos. Son propiamente aquello que denominaríamos «fantasmas»y se confunden con facilidad con los Lemures, en particular en los autores más tardíos y cristianos.

4. larua (singular): Representación plástica de estos seres y, de acuerdo con su asimilación a los difuntos, representación de ellos (en la línea de los eidola y las imagines). Al menos desde el siglo I, una larua es un esqueleto, si bien adopta otras formas, como la negritud y fealdad del rostro, dada su naturaleza infernal y nocturna (quizás esto último por asimilación a los $L e$ mures). A la luz de Apuleyo, simulacra de este tipo se empleaban en rituales de magia negra.

5. larua (singular): Representación grotesca de seres sobrenaturales (demonios) que deriva en usos teatrales (máscara), posiblemente con origen ritual y apotropaico y que se mantiene en manifestaciones populares, alcanzando una larga pervivencia.

En pocas ocasiones, al menos en épocas republicana y clásica, existe una auténtica confusión de significados, que es la justificación más común para el empleo alternado de larua con otros espíritus. Bien al contrario, consideramos que todas las acepciones tienen una validez conceptual, responden a procesos de transformación y síntesis sucedidos en el tiempo y guardan coherencia en el contexto en que se emplean. 


\section{BIBLIOGRAFÍA}

Alfayé, S. 2009: «Sit tibi terra gravis, magical religious practices against restless death in the ancient world», en Marco, F., Pina, F. y Remesal, J. (coords.), Formae mortis: el tránsito de la vida a la muerte en las sociedades antiguas, Barcelona, pp. 181-216.

Bronzini, G. B. 1991: «Dalla larva alla maschera», en Bettini, M. (ed.), La Maschera, il Doppio e il Ritratto: Strategie dell'Identità, Roma, pp. 61-84.

Bucheler, E. y Riese, A. 1864: Anthologia Latina, Leipzig.

Cumont, F. 1922: Afterlife in Roman paganism, New Haven.

Cumont, F. 1949: Lux perpetua, París.

DAGR $=$ M. Ch. Daremberg y E. Saglio, Dictionnaire des Antiquités grecques et romaines, 10 vols., París, 1877-1919.

Dumézil, G. 1966: La religion romaine archaique, París.

Dupont, F. 1987: «Les morts et la mémoire: la masque funèbre», en Hinard, f. (ed.), La mort, les morts et l'au-delà dans le monde romain. Actes du Colloque de Caen 20-22 novembre 1985, Caen, pp. 167-172.

Egger, R. 1962: Romische antike und fruhes Christentum I, Klagenfurt.

Ernout, A. y Meillet, A. 1932: Dictionnaire Etymologique de la Langue Latine, París.

Espinosa, T. 2006-2007: «Una aproximación a las creencias populares de los romanos: las Lemurias ¿respeto o temor?» Serie II, Historia Antigua 19-20, pp. 257-269.

Faraone, Ch. A. 1993: Masks of Dionysus, Ithaca.

Felton, D. 1999: Haunted Greece and Rome: ghost stories from classical antiquity, Texas.

Gil Fernández, J. 1971: Séneca, Apocolocintosis: introducción, texto, aparato crítico, traducción y notas. Suplementos de «Estudios Clásicos». Segunda serie de textos: número 4, pp. 105-203.

Hedreen, G. 2007: «Involved spectatorship in archaic Greek art», Art History 30.2, pp. 217-246.

Hidalgo, M. J. 2009-2010: «Larvas, Lemures, Manes en la demonología de Apuleyo y la creencias populares de los romanos», Arys 8, pp. 165-186.

Hunink, V. 1996: «Notes on Apuleius Apology», Mnemosyne 49, pp. 159-167.

Iles Johnston, S. 1995: «Defining the dreadful: remarks on the Greek child killing demon», en Meyer, M. y Mirecki, P. (eds.), Ancient Magic and ritual power, Boston-Leiden, pp. 361-387.

Jobbé-Duval, E. 1924: Les morts malfaisants «larvae, lemures» d'apres le droit et les croyances populaires des Romains, París.

Kropp, A. 2008: Defixiones: ein aktuelles corpus lateinischer Fluchtafeln, Speyer.

Lessing, G. E. 1769: Wie die Alten den Tod gebildet, Berlín (reed. inglesa Lakoon and How the Ancients Represented Death, Londres, 1914). 
Lindsay, W. M. (ed.) 1903: Nonio Marcelo, De compendiosa doctrina, Teubner, Leipzig.

Lux, J. 2004: Examination of the Lemures and the Lemuria, Tesis de Grado, University of Florida. 〈http://etd.fcla.edu/UF/UFE0005482/lux_j.pdf〉 (15/08/2011).

Marco, F. 2010: «Ante dies novem: sobre un cómputo temporal mencionado en algunos textos mágico-religiosos», Serta Palaeohispanica J. de Hoz. Palaeohispanica 10, pp. 570-590.

Martínez Maza, C. 2000: «Seres intermedios y religiosidad popular en el mundo romano», en Cruz Andreotti, G. y Pérez Jiménez, A. (coords.), Seres intermedios: ángeles, demonios y genios en el mundo mediterráneo, Madrid, pp. 119-150.

Meuli, K. 1975, Gesammelte Schriften, Basilea-Stoccarda, 2 vols.

O’ Brien, R. 1924: Madness in Ancient Literature, Brown.

Odgen, D. 2008: Night's black agents: witches, wizards and the dead in the ancient world, Londres.

Parkes Weber, F. 1910: Aspects of death and their effects in the living, Londres.

Paschall, D. M. 1939: The Vocabulary of Mental Aberration in Roman Comedy and Petronius, Baltimore.

Patera, M. 2005: «Comment effrayer les enfants: le cas de Mormô / Mormolukê et du mormolukeion», Kernos 18, pp. 371-390.

Preisendanz, K. 1935: «Nekydaimon», RE 16.2, pp. 2239-2266.

Riess, E. 1941, «Notes on Plautus», Classical Quarterly 35, pp. 150-162.

Rohde, E. 1925: Psyche. The cult of souls and the belief of inmortality among the Greeks, Londres.

Rose, H. J. 1930: «Ancient Italian beliefs concerning the soul», Classical Quarterly 24, pp. 129-135.

Rubio, L. (ed.) 1978: Apuleyo. El asno de oro, Madrid, Biblioteca Clásica Gredos.

Stock, F. 1996: «Follia e malattie mentali nella medicina romana», ANRW II 37.3, pp. 2282- 2410 .

Stramaglia, A. 1990: «Due storie di fantasmi raccontate da fantasmi? PMich Inv. 3378 (Pack2 2629) e Apuleio, Met. IX, 29-3», Zeitschrift für Papyrologie und Epigraphik 84, pp. 19-26.

Stramaglia, A. 1999: Res inauditae, increduale. Storie di fantasmi nel mondo grecolatino, Bari.

Suárez de la Torre, E. 2000: «La noción de daimon en la literatura de la Grecia Arcaica y Clásica», en Cruz Andreotti, G. y Pérez Jiménez, A. (coords.), Seres intermedios: ángeles, demonios y genios en el mundo mediterráneo, Madrid, pp. 47-88.

Taylor, L. R. 1925: «The mother of the Lares», American Journal of Archaeology 29, 3, pp. 299-313. 
Thaniel, J. 1973: «Lemures and Larvae», The American Journal of Philology 94.2, pp. 182-187.

Uría Varela, J. 1997: Tabú y eufemismo en Latín, Ámsterdam.

Walde, A. 1906: Lateinisches etymologisches Wörterbuch, Heidelberg.

Winkler, J. 1980: «Lollianos and Desperadoes», Journal of Hellenic Studies 100, pp. $155-181$.

Fecha de recepción de la primera versión del artículo: 27/03/2012

Fecha de aceptación: 17/09/2012

Fecha de recepción de la versión definitiva: 22/10/2012 